Diversity-oriented pyrazol-3-one synthesis based on hydrazinodipeptide-like units prepared via the Ugi reaction

Ekaterina Lakontseva and Mikhail Krasavin*
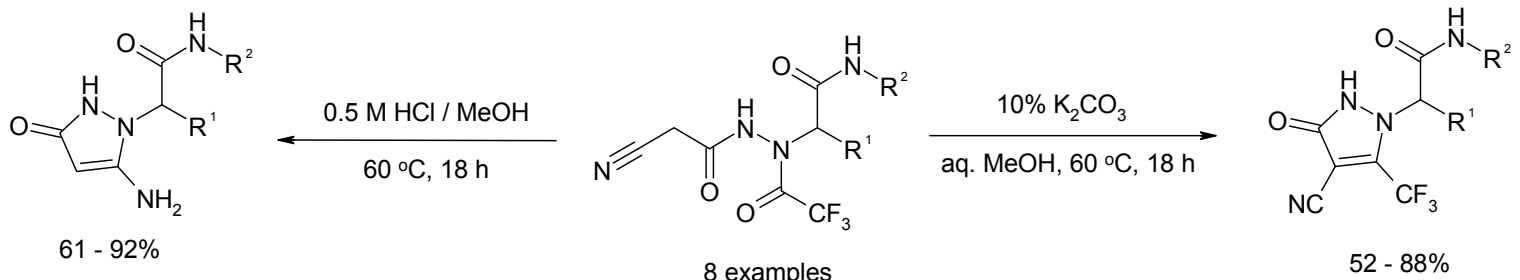


\section{Diversity-oriented pyrazol-3-one synthesis based on hydrazinodipeptide-like units prepared via the Ugi reaction}

Ekaterina Lakontseva and Mikhail Krasavin*

Science and Education Center "Innovative Research", Yaroslavl State Pedagogical University, 150000, Russia

Chemical Diversity Research Institute, 2a Rabochaya St., Khimki, Moscow Reg., 141400, Russia

*Corresponding author, e-mail: myk@chemdiv.com, phone: +7(495)995-4944, fax: +7(495)6269780.

Abstract: $N$-Cyanoacetyl- $N$ '-trifluoroacetyl- $N$ '-alkylhydrazines, prepared via hydrazino-Ugi reaction, provided different pyrazol-3-ones when exposed to mildly acidic and mildly basic conditions at $60{ }^{\circ} \mathrm{C}$. These approaches offer a facile access to two different pyrazol-3-onecontaining chemotypes in a diversity-oriented fashion, in only two chemical operations from simple precursors.

Keywords: multi-component reactions, post-Ugi modifications, hydrazino-Ugi reaction, monoalkylated pyrazol-3-ones, peptidomimetics, diversity-oriented synthesis.

Reaction of hydrazine or substituted hydrazine with 1,3-dicarbonyl compounds or synthetic equivalents thereof ( $\beta$-oxoesters, $\beta$-oxonitriles, $\beta$-dialkylamino- or $\beta$-alkoxyvinyl ketones) is a classical way to pyrazole cores known as the Knorr pyrazole synthesis. ${ }^{1}$ We have reported $^{2}$ on the preparation of hydrazinodipepetide-like units 1 via Ugi reaction involving trifluoroacetic acid as the acid component. The hydrazino-Ugi reaction initially yields hydrolytically prone trifluoroacetamides $\mathbf{2}$ which are isolable and can also be converted in situ

into 1 (Scheme 1). As the compounds 1 can contain labile $N^{\beta}$-acyl groups (such as Ac or Boc), we thought it important to explore the potential of compounds $\mathbf{1}$ as synthons in the Knorr pyrazole synthesis as such an approach may provide novel pyrazoles regiospecifically decorated 
with substituted acetamide side chains (to our knowledge, no reliable strategy to this end has been reported in the literature).

To our surprise, initial attempts to realize this approach were generally not very successful. First we tried to perform a stepwise condensation ${ }^{3}$ of representative compound 1a with cyanoacetone. While the enamine adduct $\mathbf{3}$ appeared to form (according to TLC analysis), addition of an equimolar amount of conc. $\mathrm{HCl}$ led only to the formation of (DL)- $N$ '-cyclohexyl$N$-aminoleucineamide 4 . The latter could be condensed directly with aliphatic $\alpha$-cyanoketones to give moderate yields of single regioisomers (as confirmed by HSQC spectra) of pyrazoles $\mathbf{5 a} \mathbf{a} \mathbf{b}$ (Scheme 2). However, the range of suitable condensation partners for $\mathbf{4}$ appeared rather limited: for instance, we observed no reaction with bis-electrophiles 6-8 that we had previously condensed quite efficiently with hydrazine. The reasons for the inert character of $\mathbf{4}$ in these condensations are unclear. It can be rationalized by the steric bulk on one of the hydrazine nitrogen atoms (this should not preclude the compound from reacting at $N^{\beta}$ ). It is also possible that the secondary amide functionality deactivates $N^{\beta}$ as well, via intramolecular hydrogen bonding (Figure 1).

Prompted by these observations, we designed pyrazole precursors 9 containing both an electrophilic nitrile functionality and a reactive $N^{\alpha}$ atom (which we had shown previously to be a suitable reactive center for reductive amination ${ }^{2}$ and a second Ugi reaction ${ }^{4}$ ). These precursors for intramolecular cyclization ${ }^{5}$ (presumably, into 1-alkyl-5-amino-1,2-dihydro-3H-pyrazol-3ones 10) could be derived from the hydrazino-Ugi reaction products $\mathbf{1 1}$ by facile removal of the trifluoroacetyl group (Figure 2). Such methodology was expected to explore the potential of post-condensation modifications of the hydrazino-Ugi core, an approach that had yielded numerous novel heterocyclic scaffolds when applied to classical Ugi products. ${ }^{6}$

However, when compounds $\mathbf{1 1}$ were prepared (notably, this further extends the scope of the hydrazino-Ugi reaction) and trifluoroacetyl group removal was attempted, the isolated products were the unexpected (and hitherto not described) 1-alkyl-3-oxo-5-(trifluoromethyl)-2,3- 
dihydro- $1 H$-pyrazole-4-carbonitriles 12. Under the typical conditions we had used ${ }^{2}$ for $\mathrm{CF}_{3} \mathrm{CO}$ group removal $\left(10 \% \mathrm{~K}_{2} \mathrm{CO}_{3}\right.$ in aqueous methanol, r. t., 3 hours) the conversion was slow (>3 days). Hence, the temperature was raised to $60^{\circ} \mathrm{C}$ to increase the rate of reaction. In contrast, treatment with $0.5 \mathrm{M} \mathrm{HCl}$ in aqueous methanol at the same temperature led to the expected removal of the $\mathrm{CF}_{3} \mathrm{CO}$ group and clean formation of the pyrazol-3-ones $\mathbf{1 0}$ (Scheme 3). The isolated yields of both sets of pyrazol-3-ones $\mathbf{1 0}$ and $\mathbf{1 2}$ were good to excellent (Table 1). In some cases, products of analytical purity were isolated by simple filtration, whilst in other cases additional crystallization or column chromatographic purification was required. The structure of all the synthesized compounds were supported by ${ }^{1} \mathrm{H}$ and ${ }^{13} \mathrm{C}$ NMR spectra, LCMS data and elemental analysis. ${ }^{7}$

Mechanistically, the unexpected formation of $\mathbf{1 2}$ under basic conditions can be rationalized by deprotonation at the activated methylene group of $\mathbf{1 1}$ with subsequent cyclization onto the $\mathrm{CF}_{3} \mathrm{CO}$ group to give, after dehydration, the observed pyrazol-3-one 12. Given the labile character of the trifluoroacetamide, the cyclization may be preceded by $N \rightarrow C$ migration of the $\mathrm{CF}_{3} \mathrm{CO}$ group (Scheme 4).

The ability of $\mathbf{1 1}$ (or 9) to undergo cyclization into the pyrazol-3-one should depend on the steric bulk both at the activated methyl group of the cyanoacetyl side chain and at $N^{\alpha}$. We discovered that the products 13a, b (Figure 3) synthesized via hydrazino-Ugi reaction from acetone and cyclohexanone as the carbonyl component, respectively, were completely inert toward such cyclization under acidic or basic treatment, and only provided the respective detrifluoroaceted products. Moreover, we found that even a small substituent such as a methyl group, when located at the methylene group of $\mathbf{1 0}$ (presumably, involved in cyclization path leading to 12) can affect the outcome of further cyclizations. The compound $\mathbf{1 4}$ (also prepared via hydrazino-Ugi reaction) still provided an excellent yield of pyrazol-3-one $\mathbf{1 5}$ when treated with dilute acid (Scheme 5). Under basic conditions, it yielded a complex mixture of products (including 15), none of which contained a trifluoromethyl group. 
An interesting result was obtained with the cyclopropane derivative 16. Under basic conditions, it cyclized to give a good yield of 6-alkyl-7-imino-5,6-diazaspiro[2.4]heptan-4-one $\mathbf{1 7}$ (despite the even greater steric bulk at the nitrile function). Acidic treatment of $\mathbf{1 6}$ resulted in cycloprapane ring-opening and isolation of 2-chloroethyl derivative $\mathbf{1 8}$ in fair yield (Scheme 6).

In summary, we have reported on a remarkable case of a switch in reactivity observed for the hydrazino-Ugi reaction products $\mathbf{1 1}$ under basic vs. acidic conditions. This resulted in diversity-oriented access to two vastly different pyrazol-3-one-based chemotypes, one of which 12 has not been described in the literature. The absence, in these protocols, of regiochemical ambiguity with regard to alkylation of the pyrazol-3-one nucleus and the technical simplicity of its construction in two steps from available diverse reagents should make the described approach the method of choice to prepare these novel peptidomimetic pyrazol-3-ones.

Synthesis of 11; typical procedure: Cyanoacetylhydrazine (10 mmol) was dissolved in anhydrous $\mathrm{MeOH}(50 \mathrm{~mL})$ and an aldehyde $(11 \mathrm{mmol})$ was added. The mixture was stirred at r.t. for $3 \mathrm{~h}$ and the solvent was evaporated. The solid residue was triturated with $\mathrm{Et}_{2} \mathrm{O}$, filtered, and dissolved in dry 1,4-dioxane (20 mL). Isocyanide (12 mmol) and TFA (11 mmol) were added and the resulting mixture was stirred at r.t. overnight. It was then diluted with $\mathrm{H}_{2} \mathrm{O}(100 \mathrm{~mL})$ and extracted with $\mathrm{CH}_{2} \mathrm{Cl}_{2}$ (3 x $50 \mathrm{~mL}$ ). The combined organic extract was dried over anhydrous $\mathrm{MgSO}_{4}$, filtered and concentrated in vacuo. The crude product was triturated with $\mathrm{Et}_{2} \mathrm{O}$, filtered and air-dried to provide analytically pure 11, or further purified by column chromatography $\left(\mathrm{SiO}_{2}\right)$ using an appropriate gradient of $\mathrm{MeOH}$ in $\mathrm{CH}_{2} \mathrm{Cl}_{2}$ as eluent.

Synthesis of 10; typical procedure: Compound 11 (0.5 mmol) was dissolved in $\mathrm{MeOH}(10$ $\mathrm{mL})$, treated with $0.5 \mathrm{M} \mathrm{HCl}(1 \mathrm{~mL})$ and the resulting solution was stirred at $60{ }^{\circ} \mathrm{C}$ overnight. Upon cooling to r.t., the $\mathrm{MeOH}$ was evaporated and the residue diluted with $\mathrm{H}_{2} \mathrm{O}(20 \mathrm{~mL})$, neutralized with solid $\mathrm{Na}_{2} \mathrm{CO}_{3}$, and the resulting precipitate was filtered and air-dried. Alternatively, the aqueous mixture was extracted with $\mathrm{CH}_{2} \mathrm{Cl}_{2}(3 \times 10 \mathrm{~mL})$ and the combined organic extract was dried over anhydrous $\mathrm{MgSO}_{4}$, filtered and concentrated in vacuo. The crude 
product was purified by column chromatography $\left(\mathrm{SiO}_{2}\right)$ using an appropriate gradient of $\mathrm{MeOH}$ in $\mathrm{CH}_{2} \mathrm{Cl}_{2}$ as eluent.

Synthesis of 12; typical procedure: Compound 11 (0.5 mmol) was dissolved in $\mathrm{MeOH}(10$ $\mathrm{mL})$, treated $10 \%$ aq. $\mathrm{K}_{2} \mathrm{CO}_{3}(5 \mathrm{~mL})$ and the resulting solution was stirred at $60{ }^{\circ} \mathrm{C}$ overnight. Upon cooling to r.t., the $\mathrm{MeOH}$ was evaporated and the residue diluted with $\mathrm{H}_{2} \mathrm{O}(20 \mathrm{~mL})$, neutralized with $\mathrm{HCl}$, and the resulting precipitate was filtered and air-dried. Alternatively, the aqueous mixture was extracted with $\mathrm{CH}_{2} \mathrm{Cl}_{2}(3 \times 10 \mathrm{~mL})$ and the combined organic extract was dried over anhydrous $\mathrm{MgSO}_{4}$, filtered and concentrated in vacuo. The crude product was purified by column chromatography $\left(\mathrm{SiO}_{2}\right)$ using an appropriate gradient of $\mathrm{MeOH}$ in $\mathrm{CH}_{2} \mathrm{Cl}_{2}$ as eluent.

Acknowledgement. This research was supported by the Federal Agency for Science and Innovation (Russian Federation Government Contract 02.740.11.0092). Dr. Alexei Shumsky of Chemical Diversity Research Institute is thanked for his help in structure elucidation by NMR.

\section{References and Footnotes}

1. (a) Sakuya S. M. In Name Reactions in Heterocyclic Chemistry. Li, J.-J.; Corey, E. J., Eds.; J. Wiley \& Sons, Inc., Hoboken, 2005, 292-300; (b) Yet, L. Progr. Heterocycl. Chem. 2009, 21, 224-260 and references cited therein.

2. Krasavin, M.; Bushkova, E.; Parchinsky, V.; Shumsky, A. Synthesis 2010, 933-942.

3. Krasavin M.; Konstantinov, I. O. Lett. Org. Chem. 2008, 5, 594-598.

4. Bushkova, E.; Parchinsky, V.; Krasavin, M. Mol. Diversity 2010, in press. DOI: 10.1007/s11030-009-9200-6.

5. El-Hawash, S. A. M.; El-Mellah, A. I. Pharmazie 1998, 53, 368-373.

6. Akritopoulou-Zanze, I.; Djuric, S. W. Heterocycles 2007, 73, 125-147 and references cited therein.

7. Characterization data for selected compounds: 10a, white solid, $\mathrm{mp}=128-130{ }^{\circ} \mathrm{C} .{ }^{1} \mathrm{H}$ NMR (400 MHz, DMSO-d $\left.)_{6}\right) \delta .82(\mathrm{~d}, J=6.6 \mathrm{~Hz}, 3 \mathrm{H}), 0.86(\mathrm{~d}, J=6.6 \mathrm{~Hz}, 3 \mathrm{H}), 1.22(\mathrm{~s}$, 9H), 1.30 (m, 1H), 1.56 (m, 1H), 1.91 (m, 1H), 4.42 (m, 1H), 4.56 (s, 1H), 5.47 (br s, 
2H), 7.14 (br s, 1H), 9.35 (br s, $1 \mathrm{H}) .{ }^{13} \mathrm{C}$ NMR (100 MHz, DMSO-d 6 ) $\delta$ 21.4, 22.9, 24.3, 28.3, 49.9, 58.4, 74.3, 150.2, 161.8, 170.3. LC MS $\left(\mathrm{M}+\mathrm{H}^{+}\right) \mathrm{m} / \mathrm{z}=269$. Anal. calcd for $\mathrm{C}_{13} \mathrm{H}_{24} \mathrm{~N}_{4} \mathrm{O}_{2}$ : C, 58.18; H, 9.01; N, 20.88. Found: C, 58.26; H, 8.92; N, 20.81. 10d, white solid, mp = 117-119 ${ }^{\circ} \mathrm{C} .{ }^{1} \mathrm{H}$ NMR (400 MHz, $\left.\mathrm{CDCl}_{3}\right) \delta 1.05$ (s, 9H), 1.12 (d, $J=5.8 \mathrm{~Hz}$, 6H), 1.62 (m, 2H), 3.32 (m, 2H), 3.44 (t, $J=6.6 \mathrm{~Hz}, 2 \mathrm{H}), 3.53$ (m, 1H), 4.51 (s, 1H), 4.65 (s, 1H), 5.17 (br s, 2H), 8.11 (br s, $1 \mathrm{H}) .{ }^{13} \mathrm{C}$ NMR (100 MHz, $\left.\mathrm{CDCl}_{3}\right) \delta$ 21.6, 27.2, 29.2, 36.5, 36.6, 65.1, 67.0, 69.9, 71.1, 152.5, 165.3, 168.5. LC MS $\left(\mathrm{M}+\mathrm{H}^{+}\right) \mathrm{m} / \mathrm{z}=313$. Anal. calcd for $\mathrm{C}_{15} \mathrm{H}_{28} \mathrm{~N}_{4} \mathrm{O}_{3}$ : C, 57.67; H, 9.03; N, 17.93. Found: C, 57.60; H, 8.93; N, 17.88 . 12a, white solid, mp $=143{ }^{\circ} \mathrm{C}$ (dec.). ${ }^{1} \mathrm{H}$ NMR (400 MHz, DMSO- $\left.d_{6}\right) \delta 0.85$ (d, $J=6.6$ Hz, 6H), 1.25 (s, 9H), 1.36 (m, 1H), 1.66 (m, 1H), 2.28 (m, 1H), 4.92 (m, 1H), 7.86 (br s, 1H), 12.34 (br s, $1 \mathrm{H}) .{ }^{13} \mathrm{C}$ NMR (100 MHz, DMSO-d $\left.{ }_{6}\right) \delta 20.4,23.0,24.4,28.1,50.5$, 62.3, 79.6, 110.7, $118.0\left(\mathrm{q}, J_{C-F}=256.5 \mathrm{~Hz}\right), 133.3\left(\mathrm{q}, J_{C-F}=38.2 \mathrm{~Hz}\right), 161.6,167.0 . \mathrm{LC}$ MS $\left(\mathrm{M}+\mathrm{H}^{+}\right) \mathrm{m} / \mathrm{z}=$ 347. Anal. calcd for $\mathrm{C}_{15} \mathrm{H}_{21} \mathrm{~F}_{3} \mathrm{~N}_{4} \mathrm{O}_{2}$ : C, 52.02; $\mathrm{H}, 6.11 ; \mathrm{N}, 16.18$. Found: C, 51.96; H, 6.04; N, 16.25. 12d, white solid, mp = 152-154 ${ }^{\circ} \mathrm{C} .{ }^{1} \mathrm{H}$ NMR (400 MHz, DMSO-d $)_{6} \delta 1.03$ (d, $\left.J=5.9 \mathrm{~Hz}, 6 \mathrm{H}\right), 1.06(\mathrm{~s}, 9 \mathrm{H}), 1.58(\mathrm{~m}, 2 \mathrm{H}$ ), $3.11(\mathrm{~m}, 2 \mathrm{H})$, 3.31 (t, $J=6.5 \mathrm{~Hz}, 2 \mathrm{H}), 3.46(\mathrm{~m}, 1 \mathrm{H}), 4.43(\mathrm{~s}, 1 \mathrm{H}), 7.85$ (t, $J=5.4 \mathrm{~Hz}, 1 \mathrm{H}), 12.39(\mathrm{br} \mathrm{s}$, 1H). ${ }^{13} \mathrm{C}$ NMR (100 MHz, DMSO-d $\left.{ }_{6}\right) \delta$ 21.9, 27.3, 29.4, 35.7, 36.2, 64.7, 70.5, 70.7, 79.7, 110.6, $117.8\left(\mathrm{q}, J_{C-F}=271.3 \mathrm{~Hz}\right), 134.3\left(\mathrm{q}, J_{C-F}=38.2 \mathrm{~Hz}\right), 161.9,164.7 . \mathrm{LC} \mathrm{MS}$ $\left(\mathrm{M}+\mathrm{H}^{+}\right) \mathrm{m} / \mathrm{z}=391$. Anal. calcd for $\mathrm{C}_{17} \mathrm{H}_{25} \mathrm{~F}_{3} \mathrm{~N}_{4} \mathrm{O}_{3}$ : C, $52.30 \mathrm{H}, 6.45 ; \mathrm{N}, 14.35$. Found: $\mathrm{C}$, 52.38 H, 6.46; N, 14.41 . 
Scheme 1. The hydrazino-Ugi reaction and removal of a labile trifluoroacetyl group. ${ }^{2}$<smiles>[R]C=[O+][NH2+]NC([R])=O</smiles>
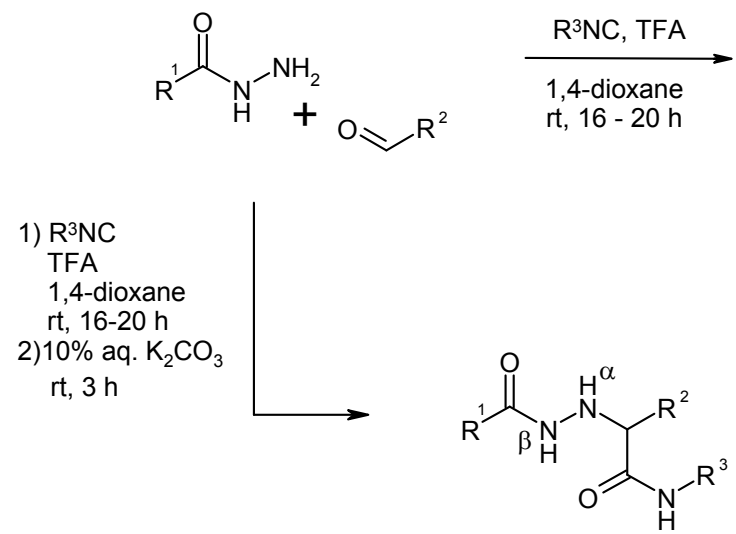<smiles>[R7]NC(=O)C([R])N(NC([R])=O)C([R])=O</smiles>

1

Scheme 2. The use of 1a as a synthon in the Knorr pyrazole synthesis.<smiles>CC(C)CC(NNC(=O)OC(C)(C)C)C(=O)NC1CCCCC1</smiles>

1a<smiles>[R]c1cc(N)n(C(CC(C)C)C(=O)NC2CCCCC2)n1</smiles>

$5 a, R=t-B u, 44 \%$

5 b, $R=1$-adamantyl, $52 \%$

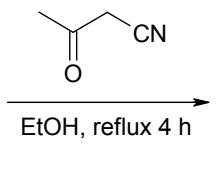<smiles>C/C(=C\C#N)N(NC(=O)OC(C)(C)C)C(CC(C)C)C(=O)NC1CCCCC1</smiles>

3

1) $\mathrm{HCl}$ in 1,4-dioxane 2) neutralize

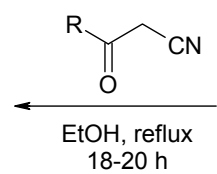

$18-20 \mathrm{~h}$
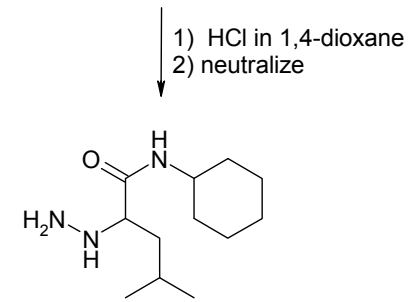<smiles>Cc1cc(N)nn1C(CC(C)C)C(=O)NC1CCCCC1</smiles>

$10 \%$ aq. $\mathrm{K}_{2} \mathrm{CO}_{3}$ $\mathrm{rt}, 3 \mathrm{~h}$

4

Scheme 3. Hydrazino-Ugi reaction of cyanoacetyl hydrazine and further transformations of the products 11.<smiles></smiles>

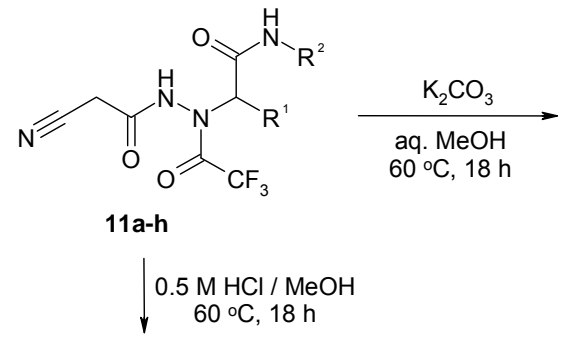<smiles>[R]NC(=O)C([R])n1[nH]c(=O)c(C#N)c1C(F)(F)F</smiles><smiles>[R]NC(=O)C([R])n1[nH]c(=O)cc1N</smiles> 
Scheme 4. Mechanistic rationale for the formation of the pyrazol-3-ones 12.

(a)

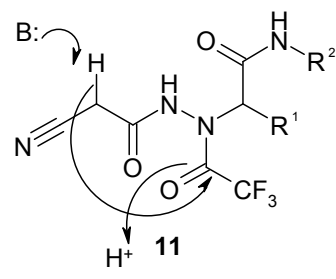

(b)

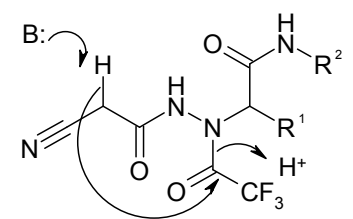

11

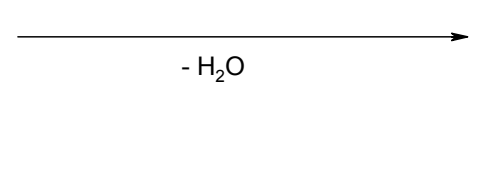<smiles>[R]C(C(=O)NC([R])C(F)(F)F)n1[nH]c(=O)c(C#N)c1C(F)(F)F</smiles>

Scheme 5. Cyclization of $\alpha$-methyl derivative 14.<smiles>CC(C#N)C(=O)NN(C(=O)C(F)(F)F)C(C(=O)NC(C)(C)C)C1CCCCC1</smiles>

14

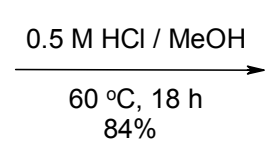
$84 \%$

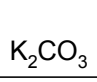

aq. $\mathrm{MeOH}$ $60^{\circ} \mathrm{C}, 18 \mathrm{~h}$ $<40 \%$

Scheme 6. Cyclization of the cyclopropane derivative 16.

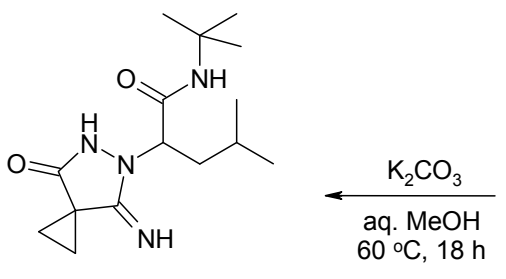

17, $70 \%$<smiles>CC(C)CC(C(=O)NC(C)(C)C)N(C(=O)C(F)(F)F)C(=O)C1(C#N)CC1</smiles>

16<smiles>Cc1c(N)n(C(C(=O)NC(C)(C)C)C2CCCCC2)[nH]c1=O</smiles>

15

Figure 1. Suggested intramolecular hydrogen bonding in $\mathbf{4}$ and examples of unreactive biselectrophile partners.

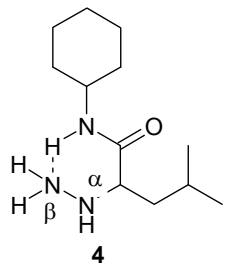<smiles>N#CC(C(=O)C(F)(F)F)c1ccccc1</smiles>

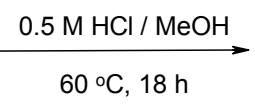

$60^{\circ} \mathrm{C}, 18 \mathrm{~h}$<smiles>CC(C)CC(C(=O)NC(C)(C)C)n1[nH]c(=O)c(CCCl)c1N</smiles>

$18,48 \%$

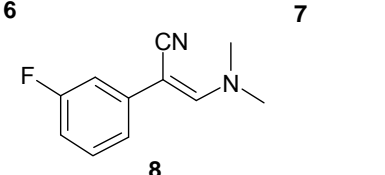


Figure 2. Cyanoacetyl hydrazine 9 designed as precursor for pyrazol-3-ones $\mathbf{1 0 .}$

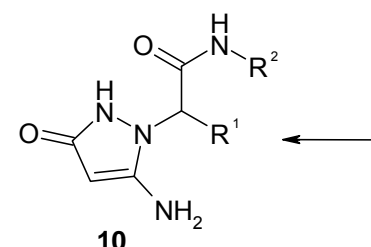

10

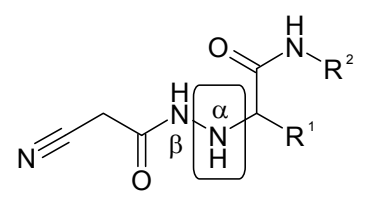

9<smiles>[R7]NC(=O)C(NNC(=O)CC#N)N(C([Z11])=O)C([R])(F)F</smiles>

11

Figure 3. Bulky hydrazine derivatives that are inert toward cyclization into a pyrazol-3-one.<smiles>CC(NC(=O)CC(F)(F)F)(C(=O)NC1CCCCC1)N(C(=O)CC#N)C(=O)C(F)(F)F</smiles>

13a<smiles>CC(C)(C)NC(=O)C1(N(NC(=O)CC#N)C(=O)C(F)(F)F)CCCCC1</smiles>

13b

Table 1. Compounds $\mathbf{1 0}$ - 12 prepared in this work.

\begin{tabular}{|c|c|c|c|c|c|c|}
\hline Entry & Product & $\mathrm{R}^{1}$ & $\mathrm{R}^{2}$ & $\begin{array}{c}\text { Yield of } 11 \\
\text { (\%) }\end{array}$ & $\begin{array}{c}\text { Yield of } \mathbf{1 0} \\
\text { (\%) }\end{array}$ & $\begin{array}{c}\text { Yield of } 12 \\
\text { (\%) }\end{array}$ \\
\hline 1 & 10a, 12a & $i-\mathrm{Bu}$ & $t-\mathrm{Bu}$ & $76^{a}$ & $52^{a}$ & $66^{a}$ \\
\hline 2 & 10b, 12b & $n-\mathrm{Pr}$ & $c$-Hex & $82^{a}$ & $69^{a}$ & $74^{b}$ \\
\hline 3 & 10c, 12c & Et & $c$-Hept & $64^{a}$ & $56^{a}$ & $77^{b}$ \\
\hline 4 & 10d, 12d & $t-\mathrm{Bu}$ & $i-\operatorname{PrO}\left(\mathrm{CH}_{2}\right)_{3}$ & $58^{b}$ & $88^{a}$ & $61^{b}$ \\
\hline 5 & $10 e, 12 e$ & $c$-Hex & $4-\mathrm{MeC}_{6} \mathrm{H}_{4} \mathrm{CH}_{2}$ & $78^{a}$ & $59^{b}$ & $89^{b}$ \\
\hline 6 & 10f, 12f & $\mathrm{Me}$ & $\mathrm{EtO}\left(\mathrm{CH}_{2}\right)_{3}$ & $68^{a}$ & $65^{b}$ & $74^{b}$ \\
\hline 7 & $10 \mathrm{~g}, 12 \mathrm{~g}$ & $i-\operatorname{Pr}$ & $4-\mathrm{FC}_{6} \mathrm{H}_{4} \mathrm{CH}_{2}$ & $47^{b}$ & $52^{b}$ & $69^{b}$ \\
\hline 8 & 10h, 12h & $c$-Hex & $t-\mathrm{Bu}$ & $83^{a}$ & $86^{a}$ & $92^{a}$ \\
\hline
\end{tabular}

${ }^{a}$ Yield of the analytically pure product isolated by filtration or by trituration with $\mathrm{Et}_{2} \mathrm{O}$.

${ }^{b}$ Yield after chromatography. 